\title{
Perspectives in Medical Research
}

Official Scientific Publication of Prathima Institute of Medical Sciences

\section{Table of Contents}

Page No.

\section{Editorial}

Oxygen Conservation Strategies in Hospital- Current Perspectives

Dr. Nikhil Mudgalkar

\section{Review Article}

Research Orientation Among Undergraduate Medical Students

Afshan Kausar

\section{Original Articles}

1. under Graduate Student's Perception of Effective Learning Experience: A Feedback Study

Nadigapu Dayanand Sanjay Kumar

2. Course and Variations in Branches of Inferior Mesenteric Artery

Gupta P, Gupta N

3. A Prospective Study Of Management of Fracture Shaft Femur by Closed Interlocking Nail in adult Goyal Ankesh,Beniwal Brijmohan,Marotia Anilkumar

4. Role of Neurosonography in evaluation of brain abnormalities in neonates

$P$ Vishwanath Reddy

5. Comparison of Flipped classroom to traditional classroom lecture in Pharmacology among second year Dental Students Vibha Rani

6. A Study on Infant Feeding Practices and Growth Assessment in Field Practice Area of PIMS, Karimnagar

Praveen Kumar

7. Spectrum of Chest Computerised Tomography (CT) findings of Covid 19 in Indian Population Boini Shravya, Vikas Chennamaneni, Vamshi Kiran Diddy, Momin Sayed Kashif

8. Study of Prevalence of Bacterial Vaginosis in Pelvic Inflammatory Disease Pallavi S.

9. A Comparative Study of Scrotal Pathologies by Ultrasound and Their Correlation with CT and MRI Thakur Hari Dayal Singh , P Keerthi Bharati

10. A Comparative Study of Pulmonary Functions in Patients with Type 2 Diabetes Mellitus and Normal Individuals Rajesh Gautam

11. Effect Of Addition Of Dexmedetomidine To Ropivacaine In USG Guided TAP Block

On Postoperative Pain In Open Appendicectomy Cases

Karampudi $K$, Waghray $K$

12. Ovarian cysts in Pregnancy: Obstetric Outcome and Management

Greeshma Singham, Achanta Vivekanand, Satyaprabha Siripurapu, Ipsita Mohapatra

Jain Neena,Bankapur Rahul,Lamba Preeti, Saurav Singh

14. A Cross-Sectional Study on Knowledge, Attitude and Practice Towards Covid-19 Among

The Parents Of Covid Positive Children Admitted At tertiary care hospital

Adarsh $E$, Nagajyothi S, Sangethya $A$ 


\section{Case Reports}

Left Atrial Myxoma Presenting As a Stroke - An Unusual Case Scenario

Mounika Pinninti, B.Syandhika,Kasturi RavinderReddy,Nikhil Mudgalkar,Ashish Baviskar

Erratum for Manuscript "Study On Neutrophil Lymphocyte Ratio And Platelet Lymphocyte Ratio In COVID-19 From Our Prospective. A Cross Sectional Study."

Guidelines for authors 